\title{
The Lopez or Citation Technique of In-Depth Collection Evaluation Explicated
}

\author{
Manuel D. Lopez
}

Based upon the brief information supplied in the article, "A Guide for Beginning Bibliographers, ${ }^{\prime \prime}$ the citation technique was utilized, on an experimental basis, by the staff of the Elizabeth Dafoe Library, University of Manitoba, Canada. While the results indicated that "this technique actually does measure the depth of the collection and consequently, would constitute a valid evaluation tool if the problems encountered could be overcome, ${ }^{\prime 2}$ that study also properly identified some of the problems inherent in the use of the instrument. However, other difficulties simply result from unidentified assumptions and inappropriate expectations of the uses of the method. Unfortunately, some of the difficulties noted are derived from the fact that the original article provided only a description of the method, but did not delineate its implementation. Perhaps some clarification of uses and limitations would be aided by a review of the citation technique of collection evaluation procedures (CTCE).

In 1979 the University Libraries of the State University of New York at Buffalo included approximately two million volumes to its shelves. These volumes served instructional and research needs primarily of graduate and professional educational programs in the schools of the humanities, social sciences, physical and health sciences (medicine, nursing, dentistry), education, and law. The University Libraries have been, since 1964 , a U.S. documents depository, and a depository for New York State documents, supplemented by a complete collection of UN publications, documents of the European Economic Community as well as extensive holdings of British and Canadian docu- ments. The microform holdings, some 600,000 items, include documents, newspapers, periodicals, dissertations, and books.

The use of the citation technique of collection evaluation method has been limited to the sociology, political science, and social work parts of the University Libraries' collections. While the "stated interests" of each department or school are expressed in the collection development policy in terms of collecting intensity, priority 1 (comprehensive level-regarded as the level necessary for creating or maintaining a "special collection") to priority 5 (minimal level-only highly selective purchases, "inadequate in quantity and variety to support undergraduate instruction"), the selection of materials also considers the needs of other departments, schools, and faculties that require, for example, publications with a sociological orientation that may not be included in the "stated interests of the Sociology Department." For the purposes of the evaluation study, those "stated interests" - sociological theory, urban sociology, small group, medical sociology, etc., that are included in the categories of priority 2 (extensive research level) and priority 3 (teaching and research) were used to establish some of the study's limits. From the Choice list of 509 outstanding books of the year (March 1978 to February 1979) that "represented works that should be considered for priority purchase," five titles approximating the "stated interests" of the Sociology Department were selected. From each, 20 titles were taken from different and staggered sections of the bibliographies to generate 100 references, representing a variety of critical bibliographies, to books, 
articles, documents, newspapers, dissertations, papers, proceedings, and pamphlets. This approach, hopefully, avoids the pitfall of the narrow bibliography compiled by the specialist in one aspect of a discipline. The Nisonger study used, initially, only 25 references from one bibliography, with another random sample of 25 titles from the same bibliography. One of the requirements of the Manitoba experiment was the search for " a quick and efficient method of obtaining an objective evaluation of a particular subject area." ${ }^{\prime 3}$ The use of only 50 titles, at the University of Manitoba, may have been sufficient. However, use of CTCE at SUNY Buffalo always starts with 100 titles with a potential of 400 titles to be checked. Nisonger notes that, "one of the most appealing features of this technique is that it can be carried out relatively quickly and without expending a great deal of effort." To increase the number of initial references would "nullify this benefit," of CTCE at SUNY Buffalo is based upon other premises and objectives.

The procedures of CTCE are carried out for, if necessary, the duration of one semester. The study requires that the investigator use no knowledge (such as searching acquisition files) or privileges that would not be available to the ordinary library patron working on a graduate seminar paper or dissertation. The one exception to this condition is that the investigator does not resort to interlibrary loan services but confines himself to inhouse library resources.

Specifically, each of the citations on the master bibliography is checked against the bibliographic records of the University Libraries, and when possible, the reference is physically obtained. Then the center/ middle reference in the publication's bibliography, middle chapter's list of references, or the middle/center footnote is recorded. That item is retrieved and the process repeated with the first citation in that reference's bibliography, chapter's notes, or footnotes. The third-level item, in turn, is located and the last citation in the bibliography, chapter notes or footnote is obtained. Materials listed in the records but not found on the shelves are recalled from another patron, "traced" by the circulation staff, or, if the item is not in circulation, on reserve, or being repaired, but theoretically on the shelf (SUNY at Buffalo has open stacks) that title is searched for on a weekly basis for the duration of the semester. Thus, simulation of the research process incorporates a factor of bibliographic access into the study, and the evaluation of the collection becomes, to a degree, more than simply an abstract bibliographic exercise. The lack of access to library materials may indicate the need of additional investigations concerning library security, the need for an inventory, better internal records, or that the card catalog is partially obsolete.

While a quick and minimum-effort approach to collection evaluation is very desirable, the use of just four or five hundred citations out of possibly hundreds of thousands as a basis for evaluation could easily be challenged.

\section{EVALUATING THE RESULTS}

With the assumption, for Qualitative In$\operatorname{dex} A$, that (1) each succeeding level requires a cumulative expenditure of effort on the patron/researcher's part and, (2) the material would be more difficult to obtain due to age and/or more desirable, a geometric progression of values was assigned to each level. (See table 1.)

In terms of scoring, the interpretation of procedures was perhaps more rigid than if a researcher were actually engaged in a bibliographic search. Unless the exact reference was available-not just listed in the library's bibliographic records-and met all the requirements of language, edition, editor, etc., it was rejected, and in terms of the study, considered as a negative result. The Manitoba study was more flexible in its approach, accepting an edition later than the one cited but not a previous one. This seems to be a reasonable solution-at least in the social sciences, but in the area of literary research with its emphasis upon primary sources and definitive editions, it is perhaps inappropriate.

Calculating the "source" could be done in several ways. Index $A$ could be the product of "actual" points $(2,760)$ in relation to "possible" points, $(3,900)$ indicating that 70.7 percent of the materials were 
TABLE 1

QUALITATIVE INDEX $A$

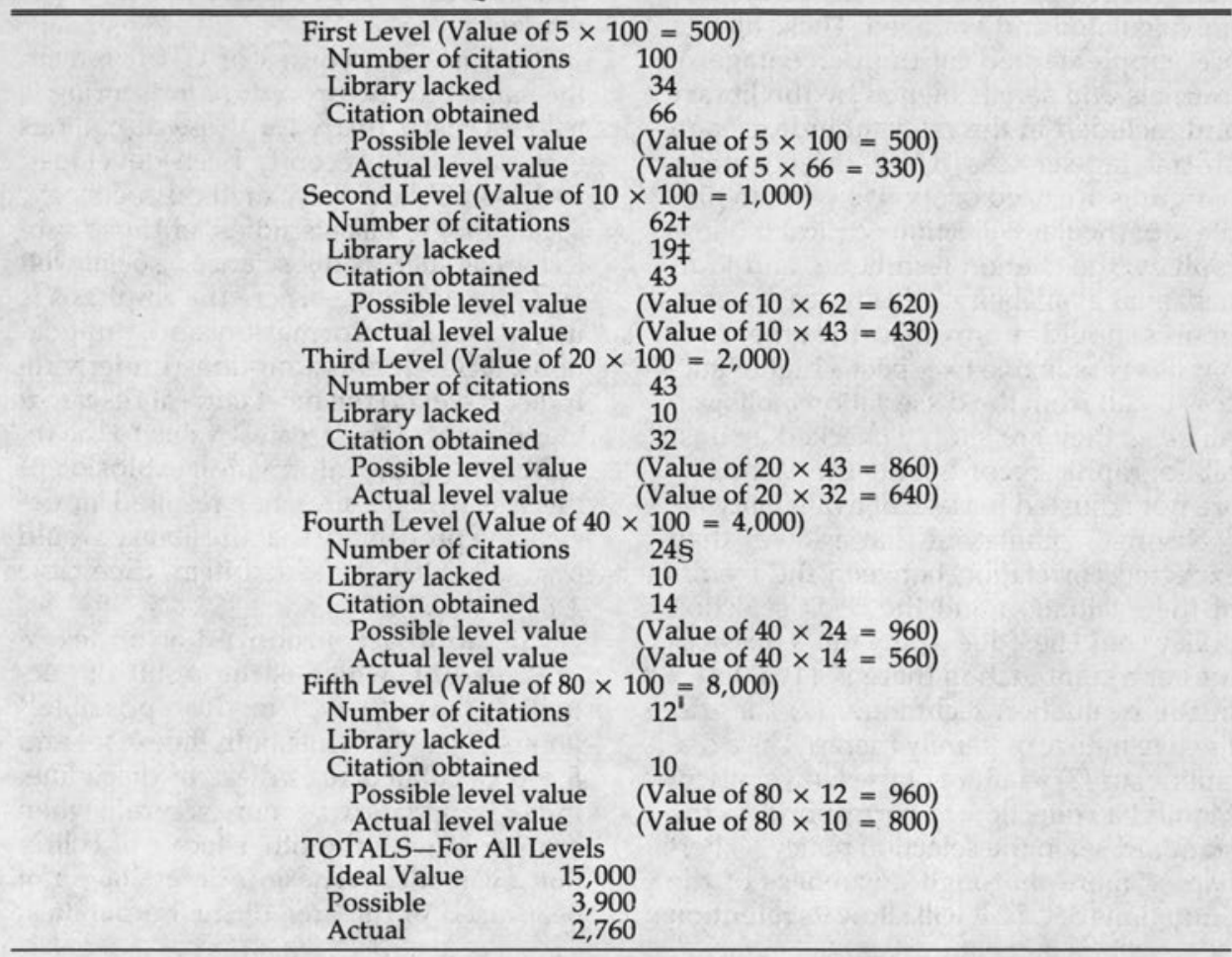

-Twenty-five titles were not owned by the libraries, another nine were listed and a weekly search for one semester failed to locate them.

tFour of the references at first level had no footnotes, bibliography, etc.

tFifteen titles were not owned by the libraries and four others listed were not located in spite of weekly searches for a semester.

SEight of the third-level citations lacked footnotes, bibliographies, etc.

Two of the fourth-level citations lacked footnotes, bibliographies, etc.

available. Or, Index $A$ could be derived from the computation of "actual" points $(2,760)$ in comparison with "ideal" points $(15,500)$, indicating that only 17.8 percent of the materials were available. The former score is more realistic, as the percentage score has been adjusted to compensate for those citations lacking references for the next level. As Nisonger points out, the lack of citations and incomplete references are characteristic of primary sources and older titles published before the conventions of scholarship became standardized. Also, some disciplines are less oriented toward such bibliographic apparatus. Consequently, Nisonger stated that for the adjusted percentage, "this figure is probably the most significant statistical measurement (at least for our purposes) because it provides the most meaningful basis of comparison between the first and second times the exercise was carried out as well as among the four subject areas. ${ }^{\prime \prime 5}$

The SUNY Buffalo experience substantiates that statement to a degree, but with this qualification: CTCE is used only every five years, and then it is only one part of the evaluation process. At the same time that this in-depth analysis is being made, four or five dissertation bibliographies that were completed at a university ranked by Gorman ${ }^{6}$ as being first in its field and approximating the "stated interests" of the relevant academic unit are checked against the library's holdings. No 
attempt is made to obtain the cited items. Percentages of held recorded references are calculated and averaged. These figures are supplemented by the percentage of journals and serials owned by the library and included in the relevant indexes and abstracting services. Thus, three sources of figures are used every five years to profile a particular collection: critical bibliographies, the citation technique, and journal/serial availability. Ideally, each set of figures should approximate the other two, but it is reasonable to expect a higher success result from the dissertation bibliographies as they are simply checked against bibliographic records and the "scores" are not adjusted for lack of availability.

Nisonger points out that a lower than expected correlation between the results of the evaluation and the book selection policy could be "due to any three possibilities or a combination thereof: (1) a defect in the evaluation technique; (2) the distinctive nature of [family therapy] as a discipline; or (3) a failure of the University of Manitoba collection to correspond to the standard set in the selection policy. ${ }^{17}$ Perhaps a more thorough awareness of the limitations of CTCE will allow its retention and even increase its value as a measure of quality with a more flexible use of its potential.

The basic procedures of CTCE remain the same but the procedure for scoring is reversed, particularly for those disciplines that have only recently been developed such as public policy, medical sociology, sociobiology, black studies, or those subject areas such as the sciences, social welfare, nursing, etc., where the emphasis is upon recent information and publications. Thus the assumptions underlying Index $B$ are: (1) the most current research/ literature is of the greatest value to the researcher, (2) the information explosion of the last two decades has resulted in decreasing probability that the library would own a particular needed item. (See table 2.)

This approach produced an index of 77.9 percent, which is the result of "actual" points $(9,490)$ in the "possible" points $(12,170)$. While both indexes $A$ and $B$ are calculated regardless of discipline, Index $B$ appears to be more accurate when compared with the other facets of collection evaluation. These indexes have not been used in the area of the humanities.

TABLE 2

QUALITATIVE INDEX $B$

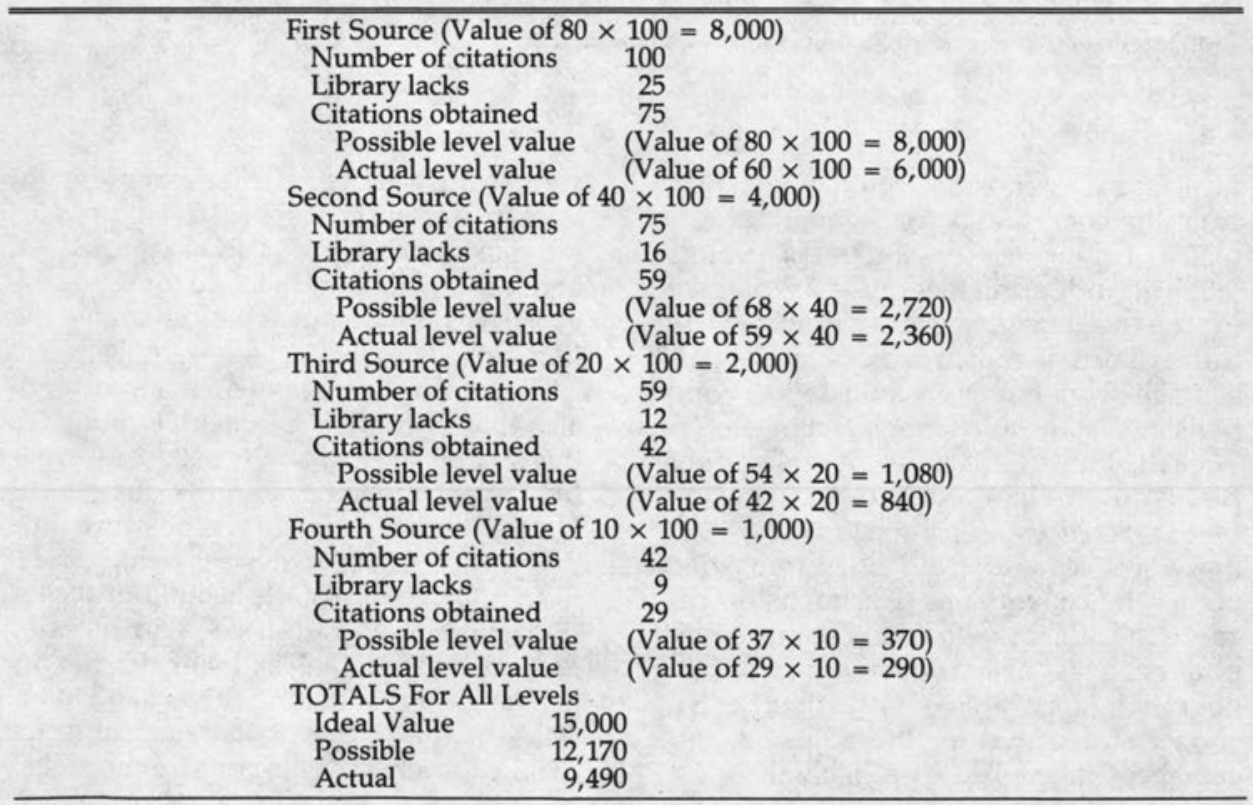


As it has already been noted, the needs of literary and fine arts investigation are extremely compartmentalized resulting in highly restrictive bibliographies inappropriate to use in CTCE situation. In contrast, as social scientists are inclined to cite in one article a range of references from Plato to Pogo, an evaluation of one social science collection becomes an evaluation of the total resources of a library.

\section{SUMMARY}

The use of CTCE has been limited, in SUNY at Buffalo libraries, to the social science collections in conjunction with the more conventional methods of collection evaluations. Periodic, at five-year inter- vals, application has supplied useful comparative data sufficiently accurate to reasonably predict the effects of modifications in funding, collection policies, etc. Unfortunately, art rather than science remains the prime factor in CTCE. The choice of the initial bibliographies to use is subjective, and vulnerable to bias and error. And the results remain a question of opinion. What is an acceptable percentage for Index $A$ ? Or should Index $B$ be used? While the answer(s), according to each institution's circumstances and objectives, will be different, however, the citation technique of collection evaluation will provide some indication of possible patron satisfaction.

\section{REFERENCES}

1. Manuel D. Lopez, "A Guide for Beginning Bibliographers," Library Resources \& Technical Services 13:462-70 (Fall 1969).

2. Thomas E. Nisonger, "An In-Depth Collection Evaluation at the University of Manitoba Library: A Test of the Lopez Method," Library Resources \& Technical Services 24:337 (Fall 1980).

3. Ibid., p.329.

4. Ibid., p.334.

5. Ibid., p.331.

6. Jack Gorman, The Gorman Report: A Rating of Graduate and Professional Programs in American and International Universities (Los Angeles: National Educational Standards, 1980).

7. Nisonger, "An In-Depth Collection Evaluation," p.336.

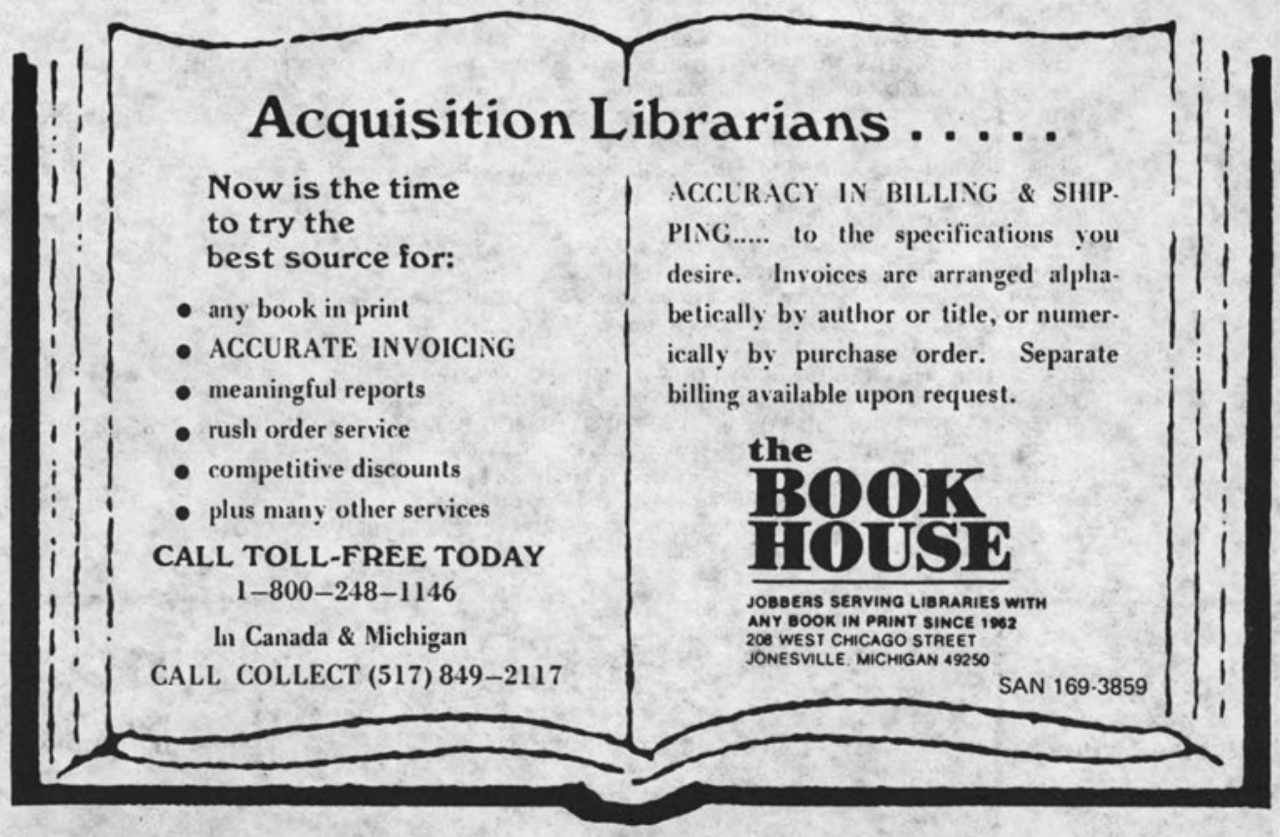




\section{New from Noyes}

\section{Available Spring 1983}

ADHESIVES TECHNOLOGY-Developments Since 1979 edited by Marcia Gutcho: ISBN 0-8155-0921-9; \$48.

ALCOHOLS TOXICOLOGY

by William W. Wimer, John A. Russell and Harold L. Kaplan: ISBN 0-8155-0948-0; \$36.

APPLIED GENETIC ENGINEERING-Future Trends and Problems by Morris A. Levin et al: ISBN $0-8155-0925-1 ; \$ 24$.

THE BIOLOGY AND MANAGEMENT OF AN EXTINCT SPECIES: PERE DA VID'S DEER edited by Benjamin B. Beck and Christen Wemmer: ISBN 0-8155-0938-3; \$26.

CHEMICAL HAZARDS TO HUMAN REPRODUCTION by Ian C.T. Nisbet and Nathan J. Karch: ISBN 0-8155-0931-6; $\$ 28$.

CLINICAL TOXICOLOGY OF AGRICULTURAL CHEMICALS by Sheldon L. Wagner: ISBN $0-8155-0930-8 ; \$ 28$.

COAL PREPARATION PLANT AUTOMATION by J.C. Moyers et al: ISBN 0-8155-0942-1; $\$ 39$.

COGENERATION TECHNOLOGY AND ECONOMICS FOR THE PROCESS INDUSTRIES edited by D.J. De Renzo: ISBN 0-8155-0932-4; \$42.

DESTRUCTION AND DISPOSAL OF PCBs BY THERMAL AND NON-THERMAL METHODS by D.G. Ackerman et al: ISBN $0-8155-0934-0 ; \$ 48$.

EDIBLE OILS AND FATS-Developments Since 1978 edited by S. Torrey: ISBN $0-8155-0923-5 ; \$ 44$.

EMERGING TECHNOLOGIES FOR THE CONTROL OF HAZARDOUS WASTES by B.H. Edwards, J.N. Paullin and K. Coghlan-Jordan: ISBN 0-8155-0943-X; $\$ 24$.

ENZYMATIC HYDROLYSIS OF CELLULOSE-Theory and Applications by C.R. Wilke et al: ISBN $0-8155-0945-6$; $\$ 24$.

FOOD ADDITIVES Recent Developments edited by J.C. Johnson: ISBN 0-8155-0935-9; \$45.

FUGITIVE DUST CONTROL TECHNOLOGY by J.A. Orlemann et al and G.A. Jutze et al: ISBN 0-8155-0933-2; \$48.

GAZELLES AND THEIR RELATIVES-A Study in Territorial Behavior by Fritz R. Walther, Elizabeth Cary Mungall and Gerald A. Grau: ISBN 0-8155-0928-6; $\$ 28$.

HANDBOOK OF INDUSTRIAL RESIDUES by Jon C. Dyer and Nicholas A. Mignone: ISBN 0-8155-0924-3; \$54.

HANDBOOK OF NUTRITION, HEALTH, AND AGING by Donald M. Watkin: ISBN 0-8155-0929-4; $\$ 32$.

HANDBOOK OF PLASTICS FLAMMABILITY AND COMBUSTION TOXICOLOGY by Arthur H. Landrock: ISBN $0-8155-0940-5 ; \$ 36$.

HORSE BEHAVIOR by George $\mathrm{H}$. Waring: ISBN $0-8155-0927-8 ; \$ 35$.

INDUSTRIAL ENERGY CONSERVATION TECHNOLOGIES \& RESEARCH OPPORTUNITIES edited by DJ. De Renzo: ISBN 0-8155-0941-3; \$64

INDUSTRIAL WATER TREATMENT CHEMICALS AND PROCESSES edited by M.J. Collie: ISBN 0-8155-0936-7; $\$ 42$.

INSECTICIDE MANUFACTURING-Recent Processes and Applications edited by M.J. Satriana: ISBN $0-8155-0920-0 ; \$ 45$.

LANDFILL METHANE RECOVERY edited by M.M. Schumacher: ISBN 0-8155-0946-4; $\$ 54$

LAND TREATMENT OF HAZARDOUS WASTES edited by James F. Parr, Paul B. Marsh and Joanne M. Kla: ISBN 0-8155-0926-X; \$45.

MICROBIOLOGICAL SYNTHESES-Recent Advances edited by S. Torrey: ISBN $0-8155-0937-5 ; \$ 48$.

REMEDIAL ACTION TECHNOLOGY FOR WASTE DISPOSAL SITES by P. Rogoshewski, H. Bryson and K. Wagner: ISBN 0-8155-0947-2; $\$ 36$.

SPILL PREVENTION \& FAILSAFE ENGINEERING FOR PETROLEUM \& RELATED PRODUCTS by J.L. Goodier, R.J. Siclari and P.A. Garrity: ISBN 0-8155-0944-8; \$36.

TEXTILE WET PROCESSES-Vol. 1: Preparation of Fibers and Fabrics by Edward S. Olson: ISBN 0-8155-0939-1; $\$ 28$.

TREATMENT, RECOVERY, AND DISPOSAL PROCESSES FOR RADIOACTIVE WASTES edited by J.I. Duffy: ISBN 0-8155-0922-7; \$39. 